\title{
No Laughter among Thieves: Authenticity and the Enforcement of Community Norms in Stand-Up Comedy
}

\author{
Patrick Reilly \\ UC Irvine, Paul Merage School of Business \\ SB2 321 \\ 4293 Pereira Drive \\ Irvine, CA 92697 \\ reillyp@uci.edu
}

Acknowledgements: I would like to thank Gabriel Rossman, Lynne Zucker, Noah Askin, Clayton Childress, Matt Darnell, David Halle, Minjae Kim, Sharon Koppman, Kyle Nelson, Gerardo

Okhuysen, Jennifer Sachs, Michael Siciliano, Ezra Zuckerman Sivan, Edward Walker, and the four anonymous reviewers for their constructive comments and thoughtful advice during my preparation of this article. An earlier version of this paper was presented at the 2015 Academy of Management Conference.

Funding: No grant or other funding was received for this project. 


\begin{abstract}
Why might observers label one social actor's questionable act a norm violation even as they seem to excuse similar behavior by others? To answer this question, I use participant-observer data on Los Angeles stand-up comics to explore the phenomenon of joke theft. Informal, community-based systems govern the property rights pertaining to jokes. Most instances of possible joke theft are ambiguous owing to the potential for simultaneous and coincidental discovery. I find that accusations are not strongly coupled to jokes' similarity, and enforcement depends mainly on the extent to which insiders view the comic in question as being authentic to the community. Thus comics who are oriented toward external rewards, have a track record of anti-social behavior, and exhibit lackluster on-stage craft are vulnerable to joke theft accusations even in borderline casesbecause those inauthentic characteristics are typical of transgressors. Vulnerability is greatest for comics who enjoy commercial success despite low peer esteem. Authenticity protects comics because it reflects community-based status, which yields halo effects while encouraging relationships predicated on respect. In exploring accusations of joke theft and their outcomes, this study illustrates how norms function more as framing devices than as hard-and-fast rules and how authenticity shapes their enforcement.
\end{abstract}

Keywords: social norms, authenticity, informal institutions, ethnography, culture, intellectual property 
Social norms are fundamental pre-conditions for collective action and order because they reflect shared expectations about proper behavior in a given situation and about appropriate punishment for deviators (Coleman 1990; Durkheim 1982; Gibbs 1965; Hechter and Opp 2001a). Some research has illustrated how, within certain communities, norms can substitute for laws in regulating behavior because community members see such norms' flexibility, ease of application, and grounding in localized practice and culture as being optimal in their setting (e.g., Ellickson 1991; Fauchart and von Hippel 2008; Oliar and Sprigman 2008; Ostrom 1990; E. Posner 2002). Nevertheless, scholars recognize that the punishment of violations in such contexts is often inconsistent. Their research tends to portray this inconsistency as deriving from deficiencies—such as costliness, lack of interdependent social relationships, poor information flow, or weak incentives for compliance-in the sanctioning process (Coleman 1990; Di Stefano, King, and Verona 2015; Fauchart and von Hippel 2008; Horne 2009).

At the same time, scholars have devoted little attention to how the ambiguity of a social norm itself and the situations it covers shapes sanctioning outcomes and may contribute to their inconsistency. There is some acknowledgment that the content and standards of norms are seldom precise and typically ambiguous (see e.g. Hechter and Opp 2001b; Jasso and Opp 1997; R. Posner 2007). However, few empirical investigations have been conducted that explore how social actors negotiate these constraints or their effects on the identification and punishment of norms violations. Yet in the absence of certain standards, the ways that individuals identify such transgressions and subsequently assign blame have clear implications for the sanctioning process and may also affect enforcement outcomes.

Drawing from 50 months of ethnographic research, I investigate the enforcement of ambiguous norms by studying joke theft in stand-up comedy. Such theft is defined as the unauthorized copying of another performer's material while falsely claiming (implicitly or overtly) 
authorship, and it is governed by comics through an informal, norms-based system of peer enforcement (see Oliar and Sprigman 2008). Comics situate the norm prohibiting it as central to their practice and community. Although many routines exhibit enough surface similarity to conceivably count as joke thefts, peer accusations of such misconduct are remarkably few; sanctions for it are rarer still. I attribute this imbalance to how insiders process possible violations, regard possible transgressors, and thereby identify wrongdoing socially. I find that the enforcement of this social norm is only loosely coupled to how much one routine actually resembles another; instead, enforcement depends more heavily on opinions about the focal comic's standing and membership in the community.

More specifically, peer enforcement depends on the recognized authenticity of the comic in question — which is evinced through one's prior pro-social behaviors, commitment to the community, craft expertise, and resemblance to the ideal of a "comics' comic". In this way peers compensate for uncertainty about the social norm's standards and the actions to which it applies. The notion is especially consequential because insiders treat the extent of authenticity as a signal of one's possible motives and of the likelihood to transgress, whether deliberately or not. Because it also informs a comic's localized status and relational goodwill, or the scope of one's respect-based social ties with peers, authenticity also shapes how norm "enforcers" interpret questionable actions as well as the costliness of sanctioning. In a sense, joke theft reflects perceptions of the joker more than of the joke itself, leading me to theorize that violations of ambiguous social norms can reflect the transgressor's membership more than the alleged transgressive act.

\section{Uneven Enforcement and Ambiguous Norms}

Why might two similar actions be punished as a norm violation in one case and excused or ignored in another? In addressing this potential variance in enforcement, scholars typically point to factors that compel or constrain the sanctioning process. Research in rational choice theory 
emphasizes that the possible costs of sanctioning transgressors—-such as risks of retaliation or the loss of social relationships_affect such decisions and their eventual outcomes (e.g., Axelrod 1986; Di Stefano et al. 2015; Heckathorn 1990; Horne 2009). Coleman (1990; see also Horne 2007) attributes possible lapses to the weakness of "meta-norms" that encourage and reward sanctioning behavior. However, norm enforcement may as reflect enforcers' emotional reactions (Di Stefano et al. 2015; Frank 1988). Still another approach focuses on aspects of the social production of a violation, such as the selective targeting of prominent reputed violators to maximize the effects of shaming strategies (Bartley and Child 2014) and publicity that propels a transgression into becoming “common knowledge" (Adut 2005).

However, the research just cited does not entirely explain why and when such variance in enforcement becomes manifest. Most previous studies begin by presupposing the existence of a recognizable transgression, but that approach ignores the possible effects of enforcers' interpretations and definitions of an observed act. Since the enforcement of norms is usually conditional and since their underlying standards and applicability can be imprecise (Hechter and Opp 2001b; Jasso and Opp 1997; R. Posner 2007), it follows that the process by which individuals navigate these obstacles to consistency could have a strong enough effect on enforcement to account for its observed unevenness. Therefore, a more complete explanation may emerge by focusing on earlier stages of the process - in particular, the stage where enforcers identify possible violations.

Some scholars emphasize that norm enforcers process and evaluate possible transgressions through interpersonal negotiation. This perspective, especially in the law and economics tradition, evolved through the study of social worlds_-such as ranching (Ellickson 1991), gourmet cuisine (Fauchart and von Hippel 2008), diamond trading (Bernstein 1992), and stand-up comedy (Oliar and Sprigman 2008) — in which social norms substitute for formal law due to the former's relative flexibility, ease of use, and low cost. In employing norms as informal rules that stipulate consensually 
constructed ideals of wrongdoing, the relevant parties negotiate to determine whether a questionable act constitutes a violation by comparing it to the standard of this informal norm (e.g., Ellickson 1991; Oliar and Sprigman 2008). In these contexts, participants consider situational factors when deciding whether an alleged transgression merits punishment and, if so, of what severity. These contributions illustrate how social norms exceed formal laws in the capacity to facilitate order and collective action in tightly knit communities. Nonetheless, this research misses important conditions of the in situ norm enforcement process. So even though social norms are viewed as informal proxies for law, these studies assume that violations entail actions that are directly relevant to the stated norm; however, it could be that violations per se comprise a wider suite of discreditable behaviors.

These shortcomings can be partially overcome by viewing the social norms observed in practice as frames rather than rules. Fine (2001; see also Goffman 1974) theorizes that frames provide participants with "templates" for interpreting situations and identifying a range of appropriate behaviors. These templates are generalizations upon which individuals rely when seeking to resolve the ambiguity of specific scenarios. When ascertaining whether an act constitutes a violation that should be sanctioned, participants consider whether it disrupts the flow of group interactions and whether certain contextual factors suggest disregard for the community's practice (see also DeLand 2013). As a result, not all questionable acts are framed as transgressions. Beyond providing a more robust understanding of how individuals deal with the ambiguity in norm enforcement, this perspective introduces the following premise: social norms are frames that encompass and articulate a wider range of behaviors than what is formally stated (see also Faulkner 2011).

That said, it is still necessary to identify the contextual cues that enforcers tend to prioritize—or to use for "filling in the blanks" — when attempting to reconcile generalized frames with specific situations. Despite the unique interactional settings within which such negotiations 
unfold, this approach has not been used to describe any relevant patterns across cases. However, it seems likely that observers weigh certain behaviors or qualities more heavily when deciding whether a given norm was violated.

I contend that enforcers place greater emphasis on the possible violator's own attributes than on the questionable act, mainly because the former are more salient and less ambiguous. Especially in the realm of moral judgment, individuals typically process observed behaviors via associative and pattern-based (Type I) thinking; such heuristics are shaped by social norms and other cultural frameworks that provide the means to articulate these intuitive responses (Haidt 2012; Lizardo et al. 2016; Vaisey 2009; see also Bicchieri 2006). A social actor's qualities may supply more proximate information useful for completing these patterns, which could become integrated into a norm's practical definition. For instance, enforcers might use status or reputation to dispel situational murkiness. McDonnell and King (2018) observe that high status and a positive reputation can produce halo effects, since these attributes speak to an individual's virtue or competence and thereby render one's actions less blameworthy. Yet high status could also lead to suspicion about the actor's motivations (e.g., Hahl and Zuckerman 2014). Still, the extent to which one is recognized as a member of a group or network may signal motivation and ability (Granovetter 1985; Uzzi 1997; Zuckerman et al. 2003). Such personal attributes, or the observable behaviors that attest to them, might well account for the interpretative aspects of norm enforcement. The influence of these attributes may persist because of their relevance to sanction outcomes. In this study's context, I therefore posit that a possible transgressor's perceived authenticity-given the range of qualities this notion encompasses-will strongly affect the enforcement of social norms under ambiguity (i.e., when standards are imprecise and their applicability is uncertain). 


\section{Authenticity}

According to sociological theory, authenticity consists of how much an audience agrees with a social actor's self-claimed identity (e.g., Carroll and Swaminathan 2000; Hahl 2016; Peterson 1997; Turner 1976). It is the socially constructed nature of this quality that encapsulates the distinction between "real" and "fake" or between "genuine" and "bullshit", which is evidenced by particular social performance routines (Fine 2004; Grazian 2005; Wherry 2008). There is a sense in which authenticity reflects perceptions of one's fit with a certain recognized type (Carroll and Wheaton 2009). Audiences and customers agree that members of communities and product groups should exhibit a stable suite of aptitudes or characteristics. However, it is the moral dimension that distinguishes authenticity from simple categorical membership. Deviating from a claimed identity significantly degrades one's perceived value and conveys the impression of fraud. In contrast, an authentic group member prioritizes intrinsic motivations and a commitment to tradition over external rewards (Hahl 2016; Johnston and Baumann 2007; Lena and Peterson 2008; Lena 2012).

In cases of ambiguous norms or uncertain behaviors, how might authenticity influence the enforcement process and its outcomes? On the one hand, it may confirm or dispel suspicions about certain social actors. For instance, experiments by Hahl and Zuckerman (2014) find that social actors denigrated high-status individuals who exhibited strong extrinsic motivation or expressed superiority over lesser counterparts, since these behaviors confirmed actors' presumptions about the inauthenticity of those with high status (e.g., Lamont 2000; Ridgeway and Correll 2006). Conversely, subjects celebrated individuals whose actions projected the impression of being pro-social and courteous. These findings suggest that audiences tend to be more generous to those whom they consider authentic yet reserve harsher judgment for presumably inauthentic individuals. The implication is that observers are more likely to interpret as norm violations the questionable actions of those whom they deem to be inauthentic. 
On the other hand, authenticity's effect on judgment may assume alternate forms and become more intense within particular communities; it is then a crucial quality that establishes group boundaries and determines group membership. Within a community whose collective identity relies on distinctions of exclusivity between in-groups and out-groups, membership norms can also serve to signal one's loyalty (Philips, Turco, and Zuckerman 2012). In addition, the threat external reward systems to intrinsically based valuations render observers more sensitive to authenticity (Hahl 2016). Under these conditions, authenticity can influence how one's behavior is perceived by peers. This connection suggests that peer enforcers within communities that have strong boundaries are more willing to punish those viewed as non-members and also are more sensitive to signals of inauthenticity when determining whether questionable behavior constitutes a violation of norms. Furthermore, the behaviors and qualities most responsible for shaping such judgments are those that reflect loyalty and commitment to the community.

Although this approach views authenticity as being distinct from status, it might prove constitutive of localized status within a community. Scholars have shown how constructed authenticity imbues certain products with enough symbolic value to become associated with high status (Fine 2004; Frake 2017; Johnston and Baumann 2007), yet much less attention has been paid to how authenticity affects the relative status of individual group members. Thornton (1996) does give the example of the British rave scene, where members whom participants deem authentic (as indicated by their knowledge of obscure electronic music and fashion) attract more opportunities to attend performances, have greater access to exclusive clubs, and are more "central" socially. However, status of this nature is community-specific. If status figures prominently in a given community, then it may go a long way toward explaining how it affects the enforcement of norms by peers. That is, status-based effects inform both the interpretation of possible transgressions and the costliness of sanctioning, especially for matters that concern only fellow community members. 
My ethnographic data on joke theft lead me to propose that peers, when deciding whether (or not) to frame questionable behavior as a norm violation, "fill in the blanks" of that framing through consideration of the focal individual's authenticity. The appeal of this heuristic may rely, in part, on morally laden presumptions - about the potential transgressor's aptitudes and motivations - that are drawn from certain types of prior observed behaviors. A perhaps more tangible effect of authenticity is its influence on one's social standing within a localized setting, as becomes manifest through the relationships and centrality that result from such standing.

\section{Empirical Case: Joke Theft among Stand-Up Comics}

Joke theft is the unauthorized use of another's material by a performer who falsely claims authorship, whether explicitly or implicitly (Oliar and Sprigman 2008; Stebbins 1992). Although this notion is most often applied to jokes' premises, it has been extended to cover punchlines, phrasing styles, and physical delivery. Because jokes can be neither copyrighted nor patented, it is left for community members to define and enforce—through a norms-based system—the informal intellectual property rights pertaining to stand-up comedy routines. In Oliar and Sprigman's (2008) investigation of joke theft, for instance, the authors illustrate how periodic changes in the wording of material performed on stage, the high transaction costs of infringement lawsuits, and difficulty in case documentation all contribute to the use of this informal regime over formal copyright protection. Another difference between these regimes is that the comedy industry's decentralized structure relegates most monitoring and enforcement efforts to interested third parties. The informal sanctions to which accused joke thieves could be subject include reputational damage, social ostracism, loss of bookings, and even physical violence.

The concept of joke theft is a fairly recent development. Until the mid-20th century, comics — who derived their livelihoods on touring circuits—-freely performed jokes that originated from other authors or were stock standards (Oliar and Sprigman 2008). Starting in the 1960s, 
however, several trends emerged that contributed to comics' greater emphasis on the exclusive ownership of material as well as to their greater sensitivity to joke theft. The first of these trends was that comics began shifting from a performance model based primarily on touring to one that relied more on television appearances and long-play comedy albums. This transition to mass media necessitated original material, established more concrete proof of authorship, and made it easier to monitor originality. Second, the birth in the 1970s of comedy clubs (centralized venues where comics performed and developed) led to more contact among comics and also to direct competition. Comics now appeared on expanded bills that frequently included more than a dozen acts appearing in succession. Representatives from television and film attended comedy clubs to scout new talent. Performing others' jokes would signal a lack of ability or, more tellingly, could deprive the original author of deserved opportunities. As the proximity among club comics occasioned the formation of tightly knit communities of shared interest and support (Knoedelseder 2009), policing joke theft intensified. Cribbing another's material conveyed one's untrustworthiness, selfishness, and disrespect, reasons enough to exclude the offender from comics' peer networks.

The third trend advancing the notion of joke theft involved the shifting definitions and standards regarding a stand-up comic's craft. In the era of touring comedy circuits, delivery was paramount. Since most comics shared a standard repertoire of jokes, assessments of quality reflected mainly the comic's expertise as a performer — as determined by such attributes as timing, physicality, quick wit, and technique. With the turn toward original material in stand-up comedy during the 1960s and 1970s, audiences and especially other comics began devoting more attention to one's ability as a writer or "jokesmith". Thus comics began to associate prowess in performing and writing as necessary components of a coherent "comedic voice" that creates a distinctive identity and perspective. Stealing jokes runs absolutely counter to this idea because it betokens the lack of a comedic voice. 
Contemporary stand-up comics and insiders do not extend respect to those who engage in joke theft, since that behavior not only signals on-stage inaptitude but also betrays other community members. Such violations can have severe consequences because most stand-up comics orient their participation, partially if not primarily, toward garnering their peers' inclusion and respect. For comics, the most fundamental and tangible form of social organization is their community and the networks enmeshed within it (Jefferies 2017; Reilly 2017). Membership and social centrality depend upon peer respect. Esteem and camaraderie are precious in a field where monetary compensation is often paltry and highly unequal (Rosen 1981). Most comics earn trivial incomes from their performances. Even those few who achieve stardom tend to earn, at best, a middle-class standard of living—notwithstanding such symbolically impressive achievements as the occasional solo television special. ${ }^{1}$ Of course, superstars earn many orders of magnitude more. Commercial success is often serendipitous and can be fleeting; in contrast, respect is perceived by comics as being both earned and durable.

Respect is also an important instrumental resource because it signifies one's expertise and leads to social centrality. The careers of comics are currently based around networks of venues and social cliques (Reilly 2017). After earning the esteem of fellow comics—that is, by being an exemplary on-stage and backstage performer — comics are more able to attract and maintain social ties based on esteem. This leads to greater visibility in the industry, more bookings, inclusion in fellow comics' projects, and more credits. Thus earning the respect of peers unquestionably facilitates a comic's career development. It follows that, because joke theft is antithetical to the respect of peers, transgressors incur significant social penalties.

\footnotetext{
${ }^{1}$ I observed a comic telling some peers about the sense of accomplishment he derived from being able to live off his earnings from stand-up comedy. Despite having two major television performances that same year, he earned only $\$ 11,000$ — which still greatly impressed the other comics (field notes, 2/28/2012).
} 


\section{Data and Methods}

The findings reported here are based mainly on ethnographic data that I collected through 50 months of participant-observer study of stand-up comics in Los Angeles, California. I conducted most of this research between February 2010 and April 2015, but I maintained face-to-face and/or Internet contact with several individuals post-study. My ethnographic work during the first six weeks was mostly observational, but I then began to perform stand-up comedy and continued to do so over the rest of the period.

I gained two advantages from performing stand-up comedy as a component of my research. First, it allowed me to gain familiarity with the processes that field participants undergo; this experience gave me a frame of reference for comprehending and interpreting their social actions. Adopting the perspective of an "observant participant" thus yielded advantages that enriched my understanding of this context because I could embody many of its core processes and experiences (Mears 2012). This approach acquainted me with key tacit knowledge about many of the technical and social aspects of the comedy world. Performing on-stage involves esoteric skills and challenges that are seldom evident to the detached observer. Understanding backstage processes_-such as how to garner show bookings, enter established networks, gain the trust of peers, and earn invitations to social or occupational rituals-is contingent on experience and knowledge of local scripts. Second, performing stand-up eased my access into this otherwise insular community by building rapport with members. As an active and evolving participant, I could explore not only open-mic nights, comedy clubs, independently produced shows, and talent showcases but also informal gatherings, parties, impromptu writing sessions, car rides between venues, and other fruitful settings. I conducted fieldwork three nights per week on average; that is slower than the pace of most aspiring comics, who hustle every night to perform or network. Even so, I was able to become familiar with the field site along with its defining processes and social dynamics. 
I interpreted the data, constructed theories, and oriented my ethnographic approach via abductive analysis (Tavory and Timmermans 2014). Abduction in this context involved a continual dialogue between my discoveries in the field and the relevant existing literatures. My intention was initially to engage theories concerning restricted fields of cultural production (e.g., Bourdieu 1993) and labor market tournaments in the arts (Menger 2014). Yet through my early participation in stand-up comedy I became aware of how extremely sensitive many field participants were to even the suggestion of joke theft. I was already familiar with the more highly publicized controversies involving plagiarism, but I was ignorant of this transgression's complexity and centrality to the practice and culture of stand-up comics. I learned the significance of this norm while naïvely taking field notes in the back of an LA comedy club.

Just as my pen hit the page of my small notebook, [the talent coordinator] jetted over to my direction and loudly hurled a stern directive at me: "No writing in the room!" ... I felt the eyes of all the comics shifting my way. ... Spotting the talent coordinator in his booth, I peered into his window. He looked up and smiled. "Listen," I apologized, "I am really sorry. My foul, man. I just had a slip of judgment and I was not trying to copy-." He quickly replied: "It's alright. We have to be careful. I mean, unless you are a talent agent or manager, people see someone writing, they get afraid about stealing jokes. Comics are paranoid people." I responded, “Oh, I know, I just had something to write down as a note for my thesis and-." He countered: "Dude, you could be writing a note to your girlfriend, and they will be suspicious. It's not good to have that energy." (field notes, 3/29/2010)

This inadvertent transgression—when combined with my subsequent observations of social dramas resulting from other possible violations and comics' frequent discussions about joke theft-led me to realize the local importance of this phenomenon and its potential contributions to the literatures on norms enforcement, informal property rights, and authenticity. On three separate occasions, I found myself in private discussions with peers concerning the similarity between jokes that I tried on stage and those of other performers. These instances were coincidental, not deliberate “breaching” experiments (cf. Garfinkel 1967), since it was already clear that any such deliberate 
approach would threaten my acceptance in the field. Of course, these accidental conflicts were highly informative interactions from which I drew when developing my framework.

I also conducted semi-structured interviews $(n=30)$ with a "snowball" sample of comics whom I observed directly during my ethnographic research; see Appendix A for details about the sample. These interviews offered access to information-such as experiences that occurred prior to my research window, life backgrounds, motivations, and reactions to current events within the industry — that would be more difficult to obtain within the confines of participant observation. The interview data were complementary rather than definitive, since interviewees' responses were isolated from social action (Jerolmack and Khan 2014). These data were used mainly as a lens through which to view ideal intentions. Thus I contrasted interview data with the interviewees' and their peers' observed actions to find salient instances of contradiction, which facilitated the construction of my model. Although I used open and axial coding for my field notes and interview transcripts (Strauss and Corbin 2007), I employed abductive analysis (Tavory and Timmermans 2014) when interpreting this coded data. Finally, I abstracted from the mechanisms underlying sanctions for joke theft (and other relevant norms); instead, analogical reasoning (Vaughn 2014) was used to assess their theoretical generalizability.

Public accusations of joke theft are infrequent. As chronicled by Oliar and Sprigman (2008), instances of possible joke theft are usually resolved privately. (Given the sensitive nature of these interactions, I rarely observed such negotiations directly; hence I draw from my own experiences to illustrate some key aspects of these consultations.) However, there is a high frequency of comics' references to joke theft. I often observed comics discussing and reacting to possible transgressions, both in retrospect and during actual performances of the jokes in question. Such behavior was more prominent during major controversies, in private conversations with trusted peers about possible transgressions recently witnessed, or when a comic with a discreditable reputation left the room. 
Such conversations were central to my analysis of joke theft- that is, given the highly ambiguous community standards for defining joke theft and given that the corpus of material that could be plagiarized is so vast that few (if any) participants have complete knowledge of all jokes' attributed authorship. Although it is the community that must monitor colleagues' actions, comics seldom paid much attention to others' performances. Hence it would be impossible to detect every instance of possible joke theft. When I observed a s reaction, I assumed that the infraction inducing it was severe enough to risk punishment.

In this paper, all comics in the data set are identified using pseudonymous first names. In addition, I ensured that the details given about a comic, venue, or other subject (e.g., credits, social affiliations) were general enough that confidentiality could be maintained without obscuring information pertinent to my theory's articulation. Exceptions to these procedures were made for widely publicized controversies involving celebrities, such as Carlos Mencia and Amy Schumer, to whom I shall refer by their whole names initially and thereafter simply by last names. In line with Institutional Review Board protocol, no information documented herein would adversely affect the study participants or their livelihoods.

\section{Identifying Stolen Jokes}

In 2011, Troy_ an aspiring comic — began to advance in the talent roster at a major showcase comedy club in Los Angeles. His performances at their open-mic events drew the attention of the club's talent coordinator, which earned him more consistent spots there at the more attractive times when "civilians" (i.e., non-comics) in the audience were plentiful. However, two fellow comics noticed that Troy's regular set consisted entirely of five minutes of material from a recently deceased star. After securing the support of more respected and senior performers at this club, these two comics orchestrated a show trial featuring the oblivious Troy performing his regular set. Following his set, the two comics projected a video depicting the deceased performer doing the 
exact same jokes and accompanying physical act-outs. While the audience of other comics heckled mercilessly, the two attempted to interview Troy about his obvious misconduct. Sensing that he was exposed, Troy ran out of the theater. After a video of this episode appeared on the Internet and circulated widely, he left Los Angeles and stand-up comedy altogether, never to return.

Although this incident exemplifies successful enforcement, it is far from typical. Cases of verbatim copying do sometimes occur, but most other cases of joke theft are less easy to identify because of imprecise standards and documentation difficulties. Most incidents that might be viewed as joke theft involve one comic "rewriting" others' previously performed routines, a strategy intentionally deployed to avoid accusations of copying (see also Stebbins 1992). A related complication was the high likelihood of parallel thinking even between two acts working independently of one another:

I think, to some extent, people writing the same joke is unavoidable, because parallel thinking exists. It's, like, comedy covers a set number of topics about everyday living, and people are going to have the same experiences. That's a given. (interview, Medha)

Routines that address common themes, such as those engaging stock premises or current events, are more likely to exhibit coincidental overlap. Although comics may craft their own distinctive approaches, there is a limited universe of possible humorous takes on such topics that resonate with civilians. Hence insiders tend to associate joke theft with routines exploring personal themes or featuring idiosyncratic framings or punchlines.

By definition, joke theft involves not only similarity but also an intent to make deceptive claims concerning authorship. Such claims are easily falsified in cases of verbatim copying, but intent is otherwise a speculative exercise and therefore not straightforward to establish. In the process of inferring intentions, comics express some openness to conditionality. For example, they tend not to punish novices for performing routines that strongly resemble others' material—especially jokes by star comics. They usually opt instead for a private consultation with the newcomer, who can be 
cautioned about the consequences of joke theft. Such an event occurred when, seven months into

my study, I performed a bit about how I could edit the video of me officiating a friend's wedding to make it less humiliating.

After getting off stage, [a comic] — who has a reputation for being harsh to "hacks" and comics who take shortcuts_-approached me. "Hey, Pat! Did you see Saturday Night Live last week-the one hosted by Jon Hamm?" "No, I didn't." "They had a bit about auto-tuning embarrassing events. I mean, it has some connections to that joke you have about taking solace in the fact that you can auto-tune the video of the fuck-up when you were officiating that wedding to make it better." "Oh, no!" "Don't worry, man. It happens. Watch it, and try to find the stuff from that thing you actually did that makes it different and work from there. So, if anyone tries to disrespect you and ruin your reputation by saying you stole, you can tell them to fuck off!" (field notes, 11/2/2010)

In contrast, more senior comics are sometimes apathetic to such gaffes by novices. This became clear when I observed three experienced comics watching a newcomer at a popular open-mic night.

[Ryan] cocked his head pensively and asked the three of us, "Is he doing Aziz Ansari's bit? The one about black people watching magic?” Everyone quietly processed this question and nodded affirmatively. [Greg] replied, "Yeah, but it could be a not totally novel premise." Ryan retorted, "It is really similar, right? But, I guess that he is just doing it at an open-mic." Another voice chimed in, "But, if you are going to do it in public, you have to really mix it out and make it, uh, not Aziz." Ryan sighed and said, "Well, is someone going to tell him? Oh, well. This sort of thing corrects itself. Or not." (field notes, 3/7/2016)

It is generally assumed that comics who are learning the ropes tend to perform others' jokes because they lack expertise about craft and knowledge of local customs. Newer comics are treated with some lenience if they at least seem to be trying to write their own material. Novices are rarely sanctioned because their "similar" jokes are usually viewed as being unintentional or a rookie mistake.

Given these considerations, it is hardly surprising that the number of joke theft accusations is dwarfed by the huge number of strongly similar jokes that could be viewed as cases of theft. Absent word-for-word imitation, identifying this norm violation is an inexact process owing to the ambiguity of intent and of thresholds for unacceptable similarity. The comics in my study could offer only an abstract account of the paradigmatic joke theft (see also Oliar and Sprigman 2008). 
They contend that there must be pronounced similarity, which is especially relevant for material that covers personal experiences or peculiar perspectives on routine events. The probability of parallel thinking is such that overlaps related to stock premises or current events are seldom interpreted as theft—at worst, just laziness. There must also be intent, which could be evident through obvious behavior (e.g., taking notes during another's performance). These criteria also reflect the assumption that, in the case of experienced comics, misconduct is likely to be deliberate (logical) or perhaps subconscious (psychological), since their experience should make them fully aware of craft and local customs. In practice, however, this template performs poorly at identifying which questionable acts insiders do and do not label as joke theft.

\section{Inconsistent and Selective Framing of Norm Violations}

Consider the following three bits:

I think a lot of time has passed and audiences are sophisticated now that they won't laugh at my real name. My real name is [rolls tongue for ten seconds], because my parents had a sense of humor.

-Steve Martin, Wild and Crazy Guy (1978)

I'd like to give my kid an interesting name. Like a name with no vowels...Just like forty Fs, that's his name.

-Louis CK, Live in Houston (2001)

I'd like to have nineteen kids. I think naming them, that's going to be fun...I already have names picked out. First kid—boy, girl, I don't care_-I'm naming it 'Rrrrrrrrrr'.

-Dane Cook, Retaliation (2005)

These jokes feature the same central premise of using vowel-less gibberish to name a child. Many stand-up comedy aficionados pilloried Cook as a joke thief for allegedly stealing this bit (and some other, lesser similar ones) from Louis CK. Yet Louis CK was not criticized for his version, which strongly resembles a trademark bit from one of Steve Martin's iconic (and double-platinum) albums. One might argue that the difference is that the comic (Louis CK), rather than third persons (Steve Martin's parents), names the hypothetical child. However, the inconsistent and selective attribution of joke theft cannot be reduced to the extent of similarity between jokes. 
Although the risk set of possible joke thefts is large, the frequency of enforcement is extremely low-even in cases involving material that is remarkably similar but has novel premises. ${ }^{2}$ I observed numerous instances of insiders acknowledging a comic's track record for performing jokes that are problematically similar to the work of others; however, they declined to make public accusations of theft and frequently offered post hoc excuses for these highly questionable acts. Often I heard privately corroborated narratives from multiple comics that chronicled possible (and also likely) thefts by superstar club performers. For example, multiple insiders recounted stories about Manny_a national touring headliner_taking jokes from his opening acts and even his renowned counterparts. Kim, another superstar comic, described one instance where he caught Manny red-handed performing one of his jokes:

Kim showed some ambivalence to stealing. He recalled, "Well, Manny stole one of my bits. I was headlining in Houston, and the club projected a video of previous performances before the show before people were coming in. And they had a clip of Manny from the previous week doing one of my jokes. And I did that joke the previous night, and it had fallen completely flat, and it usually kills. And Manny fuckin' killed with it. And you know what? I still made the $\$ 25,000$ for headline, and the only thing I can do is write more.” $\ldots$ [Kim] later contended that such stealing is tolerable when a person who is a "performer" takes a premise by a "writer" and crafts it into a performance rather than material. [Another comic] nodded his head and agreed. (field notes, 6/5/2011)

I also witnessed many comics explicitly referencing instances where Max, a national headliner and network television star, performed others' jokes. When interviewed, one comic recapitulated an intense conflict between Max and Saul (an aspiring performer) that other comics repeated:

Max stole one of Saul's jokes, and there was a whole beef between them. I never wanted to get involved in it. So, I heard hearsay and shit like that. I didn't want to get on one side either way, but Max stole one of Saul's jokes and did it front of him, ... And then when Saul

\footnotetext{
${ }^{2}$ One of the comics I interviewed gave some examples of strong similarities between jokes by well-known and respected performers. For this demonstration, he deliberately picked comics with peerless reputations to emphasize both the sheer number of jokes that could be construed as stolen and how many individuals received the benefit of the doubt on "parallel thought" grounds. This comic strongly believed that these similarities were purely coincidental. Following his wishes, I do not include a transcription of this interview or repeat the names he identified.
} 
confronted him, he was like, "Dude, that's my joke." And [Max] was just like, "So?" So, there was like a big thing, for a year, and [Max] went on stage and talked about how he fucked [Saul's] girlfriend before they got together. They were going back and forth, and it became a big thing to the point that people stopped kind of talking about it ... they swept it under the rug.

I overheard many insiders make coded quips or engage in backroom rants about Max's unrepentant use of others' jokes. Their gossip indicated that Max's plagiarism was more serious than Cook's transgressions_-or at least exhibited stronger similarities.

Some insiders' actions suggest that not all instances of joke theft merit sanctioning, even extreme cases. Even though many comics supported the public humiliation of Troy, some found it unnecessary despite the clear evidence of plagiarism. During the fallout from his public outing, I witnessed two comics discussing it.

Marvin: "I don't understand why people are talking about Troy. It's not like he was a celebrity. He ain’t famous!"

William: "Well, I think that the big issue is that he used to hang out here the most. And, because of that, people feel that they have to discuss it, because they attach the controversy to this place."

Marvin: "I still don't care. It's not a big deal! He is not a celebrity! You can just ignore the motherfucker!” (field notes, 6/5/2011)

In sum: not only is the framing of questionable actions as joke theft inexact and unevenly applied, but also sanctions are inconsistent and just loosely coupled to the case's severity. Although the reactions of Marvin and other like-minded comics suggest that only stars merit sanctioning for norm violations, the cases of Manny and Max show that high-status performers are seldom accused. At the same time, insiders stigmatized Cook for his routine's borderline and comparatively less egregious borrowing. Having shown that similarity does not definitively establish the occurance of joke theft, I am led to identify a mechanism that does compel peers to frame questionable behavior as a violation of norms and thence to punish the transgressor. 


\section{Authenticity as a Mechanism}

Through my ethnographic research on stand-up comics, I found that peers' recognition of an individual's authenticity strongly affected both the identification and sanctioning of joke theft. Local constructions of authenticity were the most salient mechanism enforcers used to interpret questionable acts, negotiate their ambiguity, and impute intent. Authenticity thus explains the selectivity of enforcement, since a comic's vulnerability to accusations of this norm violation—and to punishment for it — depends on the extent to which peers acknowledge him or her as a committed member of their community. I argue that the reason authenticity plays such a large role in identifying and framing transgressions is because it is the most critical determinant of peer respect and a comic's recognized membership in this community. In this section, I explain (1) how authenticity in stand-up comedy is constructed, (2) how it affects comics' vulnerability to accusations of joke theft, and (3) how it manifests in the social process of enforcement. This approach addresses the overarching questions of why enforcement seems inconsistent and why the resulting outcomes are best explained by authenticity. Authenticity and the Ideal of the Comics' Comic

Authenticity in stand-up comedy involves peer recognition of one's backstage conduct, craft expertise, work ethic, and seeming egalitarianism, all of which signal an individual's membership in and commitment to the community. Authenticity conveys that one's peers perceive the performer as truly a comic, rather than an "actor" (who pursues stand-up comedy only to secure acting work) or a "hack" (who takes the easiest route to getting laughs and thus bookings). It also reflects the premise that, notwithstanding any commercial success, comics see themselves as being primarily a stand-up comic and see other comics - irrespective of status — as peers in the same pursuit. For insiders, authenticity is the main determinant of whom they respect. 
The ideal of "the comics' comic" is perhaps the clearest articulation of authenticity in standup comedy. This notion may evoke the image of an obscure performer who "plays to the back of the room" to entertain fellow comics, rather than the civilian audience; yet its true meaning is a comic who, regardless of her celebrity, is dedicated to the craft and the community. Certain individuals epitomize this ideal.

The respect of your peers is phenomenal. To have, like, when people see Dave Chapelle come in, or Dave Attell, and the respect other comics give them, Chris Rock ... Like, they talk about Greg Giraldo like that. Everyone loved him, and he was phenomenal on stage. It was the best of both worlds. As a comic, he is a guy you can get a beer with and hang out, and he is just phenomenal on stage. (interview, Anthony)

Although technical expertise is an important aspect of this ideal, comics' comics are also adroit with respect to the community's backstage aspects. Even if already famous, they perform constantlyoften before unaccommodating crowds or for little pay-to develop new routines and refine their comedic voice. They "hang" with fellow comics, especially relative newcomers, and dispense advice or share lessons. Though comics' comics are not always personally likable, they are courteous to fellow performers. Even if they have achieved stardom, they hustle just as much and have similar priorities as before their success and as their comic peer. Comics' comics tend to define themselves mainly as stand-up comics, rather than as actors or writers who use the craft merely to expand their repertoire or to secure work elsewhere. Within the stand-up comedy community, the comics' comic ethos is a widely accepted standard for how performers should conduct themselves and for determining who is an authentic member of the community and thus worthy of respect.

Certain behaviors violate protocol and so loudly proclaim one's inauthenticity to peers. Comics view as offensive the practice of "bumping" - that is, a comic leveraging his or her higher status to intrude on an advertised bill and/or cut ahead of other comics without prior arrangement. Such behavior is especially distasteful when that comic habitually "runs the light" by exceeding the allotted stage time. Insiders also malign performers who constantly advertise their celebrity or 
commercial success and use it as a rationale to "big time" other comics or not feel obligated to participate in the backstage social world. Furthermore, some comics view as inauthentic those presumed to have taken shortcuts to success. This objection can arise even in the earliest stages: some insiders denigrate stand-up comedy classes as imperfect substitutes for the experience of learning through performing (and failing miserably) at open-mic nights. In later stages, there is a rather nebulous set of behaviors indicative of shortcuts; examples include securing overly zealous representation, relying too much on one's physical attractiveness, and not "grinding" hard enough.

As intimated previously, authenticity is not the same as being regarded as nice or personally likable. ${ }^{3}$ One seasoned comic put it this way:

You know who has the reputation for being the biggest cock? Bill Maher. So, if people like your comedy, they might overlook you being a dick, and, if they think you are an intellectual, they will overlook it. ... I guess Dane Cook is maybe that terrible combination of being super-successful, for the masses, and, on top of that, being a dick. (interview, Paul)

The deleterious effects of such anti-social behavior are moderated by other comics' admiration of the offender's material and performance. Dave Chapelle, who is highly respected among comics, has a reputation for regularly running the light for as much as an entire act. Insiders excuse this because of his craft expertise and rarified stature. In contrast, many view Cook as a hack whose material explores trite premises and reflects neither originality nor technical sophistication; ${ }^{4}$ these insiders consider Cook to be wasting time at the expense of his peers and of civilians' enjoyment.

\footnotetext{
${ }^{3}$ Insiders concede to being personal friends of inauthentic comics who are joke thieves. For example, Kim labeled Carlos Mencia, whom he counts as a friend, an "obvious" joke thief (field notes, 6/5/2011).

4 Stand-up comics distinguish "hacks" based less on the focal comic's material per se and more on one's technical competency, originality, and effort in regularly crafting new and bolder material. Some of these qualities fit the tastes of those who consume high amounts of cultural capital (Friedman 2014), but the esteem of comics rewards "virtuosity" even more - that is, even if one may not prefer or entirely understand the content. Many comics express the ethos of "funny is funny", though sometimes with exceptions for jokes that have overtly offensive (e.g., racist or homophobic) elements. Identifying comics who are hacks is a subjective process in which the standards can be inconsistent or even contradictory.
} 
I found that most comics will excuse a comics' comic for hiring joke writers because they acknowledge the necessity, when under severe time constraints, of remaining productive and maintaining a high standard of output. Furthermore, some point out that comics' comics diligently practice such material before audiences that are less than ideal in order to "make it their own" and "put it in their own voice". Nonetheless, I frequently heard insiders criticize perceived inauthentic comics for employing writers as a shortcut. It follows that a comic's perceived authenticity depends first on backstage citizenship and second on judgments of craft expertise; likability, though helpful, is not a prerequisite. Comics' comics receive and-according to insiders-deserve more generous treatment because of the respect they have earned. In contrast, inauthentic "hacks" are derided for their perceived anti-social behavior, questionable aptitude, and lack of commitment to the stand-up comic community. How, exactly, might these standards inform the identification and enforcement of joke theft?

\section{Who Might Be a Thief?}

Authenticity affects a comic's vulnerability to having his or her questionable acts framed by peers as a violation of joke theft norms. When deciding whether a transgression occurred, peers fill in the blanks of uncertain situations by considering the comic's recognized pro-social behavior, orientation, craft expertise, and other relevant qualities associated with authenticity. Performers who more resemble the idea of a comics' comic are judged more leniently. At the other extreme, inauthentic performers - especially when their commercial success has greatly outpaced their peer esteem—are especially vulnerable to harsher framings and opprobrium. These dynamics account for why insiders attribute joke theft more readily to inauthentic comics than to merely imitative ones.

This connection between inauthenticity and joke theft reflects not only how comics define such misconduct in practice but also the image of those who engage in it. A recurring theme in my 
ethnographic and interview data is the assumption that joke thieves epitomize laziness and shortcutting. As one comic explained, joke theft is wrong because

[jokes] are weapons and, frankly, pieces of intellectual, intellectual aptitude. They are intellectual feats. ... A great completed joke that always gets a pop, that has a good point of view, that has a good reversal in it, and the crowd is always surprised, and they give you a good laugh on it is a fucking feat, dude. So, I sat and slaved over that, and you are just going to take it? (interview, Terrance)

Cultivating an original routine can require months and even years of (typically unpaid) performances. Comics view joke theft as a brazen way to circumvent such toil, yet more critically they see it as showing disrespect for fellow comics and the community. In fact, insiders see joke theft as being antithetical to membership.

You see a lot of what we call wannabes. Like, hacks and thieves. A lot of people that should not be in stand-up in the first place. They dilute the craft. They piss off audiences and other performers. I don't know. There are people that just do it for stage time so that they can get an audition or a meeting. And it is not about them treating stand-up with a real seriousness or respect. (interview, Luther)

From comics' general perspective, joke theft signals a desperation for extrinsic rewards and a lack of respect for the craft, peers, and the community. I often heard comics refer to joke thieves as "sociopaths", a folk diagnosis based on the subject's orientation toward purely personal gain and concomitant disregard for other comics and for the field's own values. Insiders view such would-be members of the comics' community as inauthentic and hence unworthy of respect.

Even when the similarity between jokes is pronounced, authenticity informs peers' attribution and accusations of theft by certain individuals. As LA club comic Sam Tripoli observed, "Troy and Carlos [Mencia] get caught because they are assholes, but there is someone like [Manny] who is lovable, and those are the guys—it's very tough to catch them" (Tripoli and Redban 2011). While this statement confirms that selective enforcement reflects personal affinity, the distinction instead depends mainly on peer esteem (i.e., authenticity). Mencia, who was the subject of a widely 
publicized joke theft controversy in 2007 that severely damaged his career, exhibited all the telltale behaviors that comics associate with inauthentic comics: habitually running the light, bumping, "hackiness", and braggadocio about his initial commercial success. There were many instances of his jokes being problematically similar to those of others, but the comics in my study likened Max and Manny's questionable jokes to Mencia's standard. Even Troy's verbatim theft went practically unacknowledged for months. The comics who orchestrated his show trial told me that an additional motivation for it was Troy's anti-social behavior, which included bullying newcomers and extorting money from them for stage time, acting superior to peers, and personally slighting one of them (field notes, 6/21/2011). In contrast, insiders_especially at certain comedy clubs_consider Manny and Max to be authentic despite their acknowledged penchant for using routines that are extremely similar to others' work.

A curious prediction by an experienced comic illustrates the primacy of inauthenticity over similarity in identifying or sanctioning joke theft. Wayne, a respected comics' comic who found commercial success elusive, sometimes illustrated fame's capriciousness with the example of Lucille, then a fast-rising star who created two network television sitcoms and was a popular touring act.

Wayne: [Joke theft] is basically the comedy community ganging up and telling somebody that they didn't deserve it. Because there are little anomalies, like, I think that is going to happen to [Lucille] soon. I think, within the next two or three years, that she is going to be accused of something. And everyone will go, "Oh, that is why it happened. That is why I am not successful. It's because she cheated."

Pat Reilly: Is there any sort of indication or example?

Wayne: No, no, no! What I am saying is that she has blown up out of nowhere, and a lot of people ... think she doesn't deserve it. Nobody knows why the industry tries to anoint somebody. (interview, Wayne)

I talked to many comics who admired Lucille's work ethic and diligence, but I observed others strongly criticizing Lucille for her unwillingness to participate in backstage social circles and her perceived arrogance or because it seemed she was "too Hollywood" and sought only celebrity. 
Lucille has acknowledged these critiques in numerous interviews and even on stage. Wayne suggested that she might be accused of joke theft even in the absence of an obvious transgressionthat is, because of some insiders' distaste for her aloofness, a desire to rationalize her rapid success, localized grudges, simple jealousy, and/or resentment over her being a woman with marketable good looks in a male-dominated field. He revised this prediction after performing at a Comedy Central talent showcase and we had seen Lucille backstage at the venue. As we stood on the sidewalk of Sunset Boulevard, Wayne expanded on his previous prediction.

Wayne took a drag from his cigarette and opined, "You know, [joke theft] is about that misplaced anger that a lot of comics tend to have. When certain people get big, and there are those people every couple of years that get fucking huge in the industry, comics tend to focus negatively upon them for no reason.” (field notes, 9/28/2011)

Indeed, no public accusations against Lucille ever materialized. ${ }^{5}$ Yet the mere potential for such post hoc joke theft accusations hints at how community members could implicitly or perhaps explicitly manufacture norm transgressions. Accusations of joke theft could actually be giving voice to a whole list of grievances about perceived inauthenticity, of which appropriating another's material might be the least important. Recall that joke theft might help participants rationalize the skewed outcomes in an unpredictable entertainment industry. Finally, Lucille's case reveals just how loosely accusations of joke theft can be coupled with a bona fide transgression; they are, instead, more closely related to a successful individual's perceived inauthenticity and resulting lack of esteem within the community.

Thus insiders' assessment of a stand-up comic's authenticity affects the likelihood of one's actions being framed as joke theft. As demonstrated in the cases of Manny and Max, insiders resisted joke theft framings—despite privately admitting to highly problematic similarity—because

\footnotetext{
${ }^{5}$ I also observed comics privately ridiculing Lucille for hiring writers, even though (i) this practice is common among superstar performers and (ii) the writers she hired were comics who welcomed the opportunity.
} 
these two had earned the community's general respect. Hence their thefts did not become common knowledge, which precluded scandal (see Adut 2005). In contrast, peers had little respect for Dane Cook owing to his anti-social behavior and insiders' distaste for his on-stage performance. I found that community members' widespread aversion to Cook's on-stage and backstage behavior, especially as regards his celebrity, encouraged and validated third-party accusations of joke theft. The comic's anti-social behavior legitimized narratives of joke theft, which invited wide community punishment. These outcomes reflect such comics' perceived inauthenticity—coupled with his commercial success_-much more than they reflect the similarity between jokes.

\section{[[ INSERT Figure 1 about Here ]]}

This study's cases of possible joke theft are illustrated in Figure 1, which shows how insiders' perceptions of a comic's authenticity determine whether they view one's questionable acts as violating norms. Given that intent can never be proved and that coincidence is always possible, enforcers treat a comic's prior anti-social behavior, transgressions of other professional courtesies, presumed extrinsic orientation, and deficient craft expertise as key indicators of joke theft; in this evaluation, insiders frame the situation in accordance with prevailing social norms (e.g. Fine 2001). The components just listed_or their opposites, as applies—-help observers fill in the blanks when interpreting uncertain acts. As the leeway afforded to newcomers suggests, these components reflect the presumption of insiders that experienced comics should already be aware of proper frontstage and backstage conduct. Comics whose attributes and deficient presentation signal inauthenticity are the one most likely to transgress this norm.

Because commercially high-status comics are the most vulnerable to accusations of joke theft, the mechanisms of denigration identified by Hahl and Zuckerman (2014) shed light on the force of authenticity to shape enforcers' framing of possible norm violations. Since this interpretative process integrates other dispositional and behavioral factors, "joke theft" is a frame 
that comprises plagiarism and anything else that renders a comic inauthentic. Thus sanctions for joke theft depend not only on whether another comic's material was stolen but also, and more strongly, on who appropriated it-in other words, the extent to which a potential transgressor accords with the community's shared image of an authentic comic. These exculpatory considerations seem to render accusations of wrongdoing less likely, but how is this effect manifested in the field? How Does a Comic Come to Be Viewed As a Thief?

This section discusses how authenticity explains why only some questionable acts are labeled by peers as joke theft and subsequently sanctioned. This mechanism is a product of the relationship between authenticity and respect, which informs localized relative status within the community. Insiders can rely on authenticity as an informative signal when negotiating the uncertainty typical of possible norm transgressions and assigning blame_or blamelessness, which implies that authenticity has halo effects (McDonnell and King 2018). Note also that comics prefer to associate socially with peers who are esteemed and authentic, qualities largely divorced from the dynamics of power dependence (see e.g. Emerson 1962). The resulting relational goodwill allows authentic comics to use their social ties as tacit protection against theft accusations and sanctioning.

In a joke theft controversy, the credence that comics grant to the respective players depends in part on how much potential enforcers regard them as members of the community-or, at least, of a local network. This relation was evident, for instance, when I tried out a joke involving crystal meth use at an open-mic event I routinely attended. Afterwards, another comic privately confronted me and claimed that he had previously used the same premise. Although we arrived at an amicable resolution (I decided to shelve the joke), a group of other regular performers at the open-mic show viewed my concession as unnecessary:

[Chuck] tried to convince me that the concept was now mine, and he had faith that I would do better it than [the accuser], while alluding to the fact that he wouldn't have the ability to make his version any good. Later at the bar, Kevin exclaimed, "Fuck him!" He pointed out 
that [the accuser] likes to make people feel uncomfortable. ... Nobody seemed to care about my deed and shifted their attention to [the accuser's] poor on-stage performances and his rather obnoxious eccentricities. (field notes, 8/27/2011)

This episode illustrates a typical pattern of responses: insiders give more leeway and support to members of their social networks and the community; conversely, they tend to downplay the veracity and property rights of outsiders. It seems that, because I was a member of this venue's'subcommunity of comics, my peers were unwilling to entertain seriously the idea that I could have stolen this joke. Being part of and respected by this group lent me a "halo" in this particular case. At the same time, these insiders adjudged the claims of a peripheral and seemingly less authentic participant to be suspect. This case and other, like situations indicate that enforcers are more prone to discredit dubious outsiders. Yet such instances suggest also that some observers believe, with regard to certain joke premises, that ownership is more legitimately ascribed to comics who are more socially central and authentic.

Another case in my research gave some hints about how perceived authenticity may allow similarity to be interpreted as something other than theft. Ted, a rising comic in LA's alternative comedy scene, allegedly performed a routine at a well-attended show after ignoring a peer's warnings that it strongly resembled the distinctive bit of another comic. It wasn't long before accounts of this transgression spread through the comics' extensive social network; in the months that followed this early 2014 episode, I recurrently heard some comics reference it. I witnessed a few quips in one-onone conversations that "he might steal your material". I then asked Patterson, a comic who is close to the originator of this allegation, why nobody had confronted Ted about this open secret. He admitted: "Because everyone wants to do [Ted's] show. ... They are afraid of confrontation, and I am too. And I want to do that show" (field notes, 5/1/2014). That said, he also expressed some faith that Ted would eventually be punished in some way. 
However, comics' self-interest and desire to access or maintain resources controlled by Ted does not explain why he was not the target public allegations of joke theft. Yet his were just a few of many LA shows attracting large audiences, so being blackballed from Ted's show would do little to impair one's career development. Although comics are generally reluctant to burn bridges, Ted did not control any assets (i.e., show bookings) that comics could not receive from other sources. ${ }^{6}$ Hence his coercive power or comics' benefit maximization was not in itself sufficient to dissuade accusations.

That Ted was neither publicly accused nor sanctioned can instead be explained by the conspicuous relational goodwill of a network of peers, which lent him respect and support because he generally acted like a embodied comics' comic. His peers would regularly watch his sets, which is a rare occurrence among comics; they also interacted with him backstage and booked him on their own shows. The attention that Ted receives might be attributed to comics seeking access to resources he does control, but I observed numerous insiders expressing respect for him that was heartfelt and beyond that typically received by comics who occupy gatekeeping positions. They admired his unorthodox style, and Ted had developed bonds of mutual respect with some esteemed comics' comics—veterans of LA's alternative comedy scene. Exploiting his recognized authenticity among certain segments of his peer community, Ted cultivated relational goodwill through his social ties and achieved centrality. This behavior had the effect of providing three defenses against joke theft accusations and the attendant sanctions. First, his social ties are a highly visible signal of his acknowledged authenticity and worthiness of respect, which translate into halo effects. Second,

\footnotetext{
${ }^{6}$ There appears to be minimal preference toward peers in one's personal social circles, as I observed a few cases where comics readily labelled their friends as joke thieves. For example, Kim-who offered a rather convoluted excuse for Manny's unauthorized use of his joke-freely and publicly acknowledged that Carlos Mencia was a joke thief, even though they are "really good friends" (fieldnotes 6/5/2011).
} 
these bonds provide opportunities for retaliation-perhaps in the form of explicit revenge-against accusers or sanctions.

Third, heightened relational goodwill also give comics' comics “enhanced” avenues for marshalling conspicuous support that can reframe or delegitimize accusations of joke theft. Authentic participants in the comedy world have more ties with respected community members who can transmit and popularize preferred interpretations of accusations and questionable acts. In 2016, for example, some comics accused Amy Schumer of stealing their jokes. Interested third parties also remarked on the similarity between the closing bit of her 2015 HBO special Live at the Apollo, where she chronicled slang names for absurd sexual maneuvers, and a similar routine performed by Patrice O’Neal. Schumer denied stealing it, and she claimed that the likeness was purely coincidental because she had never watched O'Neal's original set. Moreover, several esteemed comics—including Jim Norton and Marc Maron—supported Schumer vociferously, expressed respect for her talents, and emphatically stated their judgment that she did not commit joke theft. Many attributed the accusations to uneasiness about her sudden fame and recent public support for feminist and antigun causes. The online posts of the comics in my study were split with regard to the plausibility of Schumer being a joke thief, but the majority supported her. Joke theft accusations might later stick to Schumer, but the timely support granted by esteemed comics successfully delegitimized this early round of charges.

Returning to Patterson's rationale, the lenience of peers might also reflect a fear of confrontation, especially since it could undermine the enforcer's relational goodwill within the community. Despite their strong distaste for joke theft, comics tended to associate public accusations within inauthenticity. Even in the case of Troy's egregious plagiarism, an organizer of his show trial reported to me that star comics participated in the event only because it was a response to verbatim joke theft (field notes, 6/21/2011). Despite their higher status, these comics feared that 
some observers would otherwise interpret their support as troublemakers encouraging a public shaming-behavior itself at odds with comics' norms. In fact, some comics believe that claims of joke theft mainly signal the accuser's own lack of talent.

If you are the victim of joke theft and it is something you can't get back, I wouldn't spend my time to pursue it and trying to be an officer for justice, because there are other bits. There are other jokes to be written, um, and you can write them. You have that ability. You had it! It was there! Do it again. ... And if it ran out, then maybe you have run your course as a stand-up anyway. (interview, Malcolm)

I also heard comics associate enforcement campaigns with overzealous "fanboys" or moral entrepreneurs with self-interested ulterior motives. Given the disrepute in which peers hold such confrontational behavior, comics censor accusations as way of maintaining their relational goodwill with peers, who prefer to associate with respectable counterparts and also to avoid being accused (falsely or not) of joke theft when undertaking their inescapably public creative process.

In cases of possible joke theft, enforcement outcomes depend on authenticity and thus on how respect shapes status and relationships in the community of stand-up comics. Authenticity is crucial for inferring the intent of social actors and framing their questionable actions — and also for stoking suspicion. In these respects, authenticity is clearly distinct from external status (see e.g. Hahl and Zuckerman 2014). But much as in the case of Thornton's (1996) ravers, authenticity may be the most critical aspect of a comic's localized status. One might suppose that it is only respected comics' comics who can affect norms enforcement, as when marshalling their resources to retaliate against those who accuse and sanction. Yet retaliation is possible also from superstar comics who are deemed inauthentic by peers and so should be especially vulnerable to the stigma of joke theft. After publicly accusing Carlos Mencia (whom many comics detested) of joke theft in 2007, for example, Joe Rogan was hit with a multi-year ban from The Comedy Store and found himself without a management company. 
Although retaliation is a real threat, enforcement patterns are more reflective of implicit mechanisms that manifest through shared culture and patterns of association. Authenticity influences peers' perceptions about the plausibility of joke theft, especially through status-based halo effects; it also encourages relational goodwill—especially with esteemed insiders—and thus gives a conspicuous signal of one's authenticity and local status. Such social ties also enable influential actors to alter the framing of one's questionable acts. In addition, enforcement entails reputational risks that reflect peers' distaste for accusations and sanctioning, which can be more profound when a comic whom they esteem is the target (see also Di Stefano et al. 2015). The implication is that authenticity—which encompasses behaviors that signal commitment to the community, craft expertise, prosocial orientations, and recognized membership—is a pervasive and salient mechanism because it can establish, even tacitly, how the community defines, identifies, and responds to the possible cases and perpetrators of joke theft.

\section{Scope Conditions and Future Research}

This study addresses social norms whose standards or definitions are community-specific and enforcement occurs through informal, in-group processes. My findings are most relevant to the ethical norms followed by an occupational community's members (e.g. Van Maanen and Barley 1984) and to norms followed by groups oriented toward a particular craft or realm of practice. The community I study is stand-up comedy in Los Angeles, which features (much like its New York counterpart; see Jeffries 2017) tightly clustered social networks as well as a strong overarching identity and a respect-based "economy". Although the issue of joke theft is important to stand-up comics, my research subjects freely admit that casual audiences, bookers, and entertainment industry executives are much less concerned about the issue. The structural and cultural dynamics of membership exert a strong effect on both the patterns of and mechanisms for enforcing these norms (e.g. Centola, Willer, and Macy 2005; Willer, Kuwabara, and Macy 2009). Indeed, comics 
report that "road dogs" — transient performers who perform only on tours-are known to steal frequently (especially from their opening acts)—and to limit sanctioning through coercion. These circumstances confirm that, as a mechanism, authenticity plays a special role in the setting of a tightly bound community.

Because I focus on a particular and unique field, the ideal and construction of authenticity reflect only those components related specifically to comics' observed behavior and perceived orientation. In addition to examining authenticity in other community contexts, future research could investigate how it maps onto other attributional categories—-such as gender and ethnicityand the consequences for inequality. My findings (see also Jefferies 2017) indicate that constructing an authentic comic can be constrained by gender and sexuality, but subsequent studies should further explore this dynamic in the stand-up comedy world and other contexts. My model also focuses on the potential transgressor's characteristics and not on those of enforcers. Kim and Zuckerman (2017) report that audience support for an enforcer's campaign is shaped by beliefs concerning the authenticity of the campaign's motives. Future research could analyze how transgressor and enforcer characteristics interact to affect norm enforcement processes and outcomes.

\section{Discussion}

I propose that the enforcement of ambiguous norms and the framing of uncertain acts as violations depend heavily on a social actor's perceived authenticity within a relevant community. Alternative accounts of this finding would be that comics selectively make or withhold allegations of joke theft due to the coercive power of high status peers, strategic targeting of competitors, or costbenefit considerations. My data present many instances that illustrate why such explanations prove incomplete. 
My findings do not indicate that coercive power primarily shapes enforcement patterns. Following this explanation, a community would almost never punish high-status or resource-rich comics, while low-status counterparts would be the most likely targets. However, I have found that community members have labelled star comics as norm violators, despite their fame or proximity to gatekeepers. For example, Dane Cook and Carlos Mencia occupied positions where they could have convinced bookers or entertainment industry professionals to blackball possible accusers. Yet despite their outsized potential for retribution, they were targets of joke theft allegations. Conversely, comics with limited control over resources or retaliatory capacity against accusers' careers, such as Ted, received generous treatment from peers and evaded sanction. Newcomers who performed questionably similar jokes but conveyed the impression of trying to learn the craft typically received lenience. Although some star comics have exploited their opening acts’ dependence for career opportunities by stealing their peers' material, this did not deter third parties from freely sharing information throughout the community about this unethical behavior and labelling it as joke theft (also: Oliar and Sprigman 2008). Thus, variation in joke theft accusations reflected insiders' perceptions of a comic's authenticity more than his or her capacity to retaliate.

The enforcement patterns of joke theft norms cannot be attributed to selective and strategic attacks against rivals. Opportunistic targeting would produce more allegations of wrongdoing. Although similar jokes were commonplace and provided ample opportunities to accuse competitors of theft, comics rarely did since making accusations often produced the disapproval of peers. Many informants expressed annoyance with some peers' accusations, even those of close friends, and typically perceived them as dubious or self-aggrandizing. Some comics, such as Joe Rogan (Maron 2011), have experienced backlash from peers for publicly naming and shaming joke thieves. Despite a comic's possible charitable intentions, community members were likely to dismiss peers' joke theft allegations as distasteful and self-interested acts of moral entrepreneurship (Becker 1963; Kim and 
Zuckerman 2017). I found that insiders supported joke theft allegations against inauthentic comics when the accuser appeared to be impartial and interested in collective benefit.

My research shows that enforcement processes and outcomes cannot be completely explained by cost-benefit considerations. Although conscious of the possible reputational damage and possible retaliation that may follow those who allege joke theft, comics do acknowledge and publicly decry norm violations by some superstars and personal friends, which is likely costly and high-risk behavior. I observed that the uneven peer enforcement of joke theft norms reflects how observers identify and define sanctionable behaviors prior to possible punishment. Insiders refer to authenticity to navigate ambiguous norms and to ascertain whether to frame an uncertain act as transgressive, which constrains the set of potentially blameworthy acts and, perhaps, prematurely excuses jokes that exhibit strong similarity to others' work. Therefore, focusing solely on sanctioning and its costs underrepresents the number of possible transgressive acts. While cost-benefit considerations may address the conditions in which sanctioning is likely, my findings show how community members enforce norms in situ and why certain individuals tend to receive or evade punishment. Through explaining the process by which violations come to be acknowledged and social actors locally construct the meaning, significance, and moral nature of certain behaviors, my findings complement and provide a necessary precursor for rational choice approaches (e.g. Coleman 1990; Di Stefano et al. 2015; Horne 2009).

\section{Conclusions}

Peer enforcement of the prohibition against joke theft involves community members interpreting uncertain cases in the light of imprecise and highly conditional standards and then sanctioning violators in informal institutions. Given the ambiguity involved, enforcement depends upon perceptions of a focal comic's authenticity_or lack thereof. Whereas authentic comics' comics are given significant leeway, inauthentic commercial stars who lack the community's respect are 
especially vulnerable to having even borderline transgressions framed as norm violations. Thus joke theft is a notion that encompasses and articulates a suite of inauthentic behaviors-breaches of professional courtesy, a lack of commitment to the community, and the prioritization of celebrity over craft expertise — that extend beyond the similarity between two jokes. Inauthenticity matters in norm enforcement because it casts doubt on a comic's motives and intentions. In contrast, authenticity enhances local status because it is the main prerequisite for respect. These dynamics shape the framing of possible joke theft through halo effects and relational goodwill, which confer esteem-based social ties (and thus greater social centrality) on authentic comics. Hence these individuals gain access to new ways of reframing allegations, an especially effective example of which is the defense offered by another comics' comic. Although direct retaliation—and sometimes just the threat of retaliation — can dissuade potential accusers of joke theft, the selectivity of such enforcement proves to be a consequence mainly of how the community of stand-up comics defines itself and classifies its members.

Two clear theoretical contributions follow from this examination of joke theft. First, I advance theories that address community-based norms and their enforcement by focusing upon how social actors define and identify violations. This process is complicated by the tendency of social norms to reflect ambiguous standards (Hechter and Opp 2001a; Jasso and Opp 1997). My findings indicate that, when interpreting uncertain situations, enforcers consider a social actor's attributes and behavior to be conspicuous and relevant contextual factors. This process highlights that norms constitute devices that social actors enact to ascertain or articulate the meaning of a situation, especially regarding its moral significance. This observed pattern supports the notion of norms as generalized frames - that is, rather than as directive rules applied to a presumed class of situations (Fine 2001). Thus, a norm violation seldom involves the stated misconduct only; it typically integrates various aspects of behavior and identity relevant to a given setting. It follows that 
researchers who investigate real-world sanctioning should examine a range of behaviors and qualities (surrounding the questionable action) that is wider than previously investigated.

Second, this article advances the development of "authenticity" as a sociological concept. Specifically, as it pertains to individuals rather than artifacts, I identify some avenues through which it alters judgments. For example, presumptions of authenticity can introduce or confirm suspicions about specific groupings of social actors. This idea aligns with Hahl and Zuckerman's (2014) experimental research into patterns of denigration toward high-status actors. Yet I find that, within bounded communities, localized status is driven mainly by authenticity because that quality signifies true membership. Authentic participants are thereby afforded enhanced social centrality and greater access to scarce resources. Having access (or not) to such benefits affects how peers evaluate the moral character of another's actions. Furthermore, my research reinforces that "economic disinterest" (Bourdieu 1993) is not a precondition for authenticity. In stand-up comedy, performers are devoted to their craft and community, but they still welcome the opportunity for stardom. The main point of difference is those who participate in the community solely to access external rewards - and who take shortcuts or betray local ethics to attain that goal (see also: Carroll and Swaminathan 2000; Frake 2017). In more general terms, then, this article suggests that authenticity encompasses commitment to one's community.

My findings concerning peer enforcement of joke theft also offers insight into how audiences distinguish instances of imitation and theft by cultural producers. This case reinforces the general premise that such judgments do not solely depend upon similarity in content, but rather perceptions of an author's motivation and process. It is evident in previous research. For example, the threshold between literary plagiarism and a pastiche or homage tends to follow subjective assessments of the would-be violator's "genius” or work's contributions (R. Posner 2007). However, peer enforcement of joke theft shows such judgments are not constrained to aesthetics, but they also 
reflect whether a producer's backstage behavior signals commitment to the craft or community. Constructions of authenticity can help identify the conditions under which an ambiguous normative frame, such as imitation-which is commonplace and sustains fashion (Aspers and Godart 2013; Godart 2012) and popular music (Frith 1996)_crosses a threshold to become problematic and blameworthy, which can happen in certain instances (e.g. Gardner 2016; Lieber 2018). These constructions can also explain how art worlds (Becker 1982) practically define and adjudicate the conditions of informal intellectual property rights (Fauchart and von Hippel 2008; Oliar and Sprigman 2008).

My findings offer additional perspectives on why certain norm violations do or do not occasion scandal. Adut (2005) identifies publicity of a transgression as a necessary precondition for scandal. However, peer enforcement of joke theft illustrates that the prior stages of scandal processes are where the set of potential causes célèbres emerge. Observers' perceptions of a social actor's authenticity can enable generous framings of highly problematic behavior, which can significantly delay or prevent scandals. Such dynamics were evident in my research. For example, my ethnographic data suggests that Louis CK's perceived authenticity contributed to the substantial delay in sanctioning for his sexual harassment of female comics, as narratives related to his misconduct circulated as gossip among insiders and were directly referenced on stage. Yet many insiders seemed to view his predatory behavior as more a hazard to be overcome than a grave moral transgression. While CK exploited his powerful stature in the entertainment industry to dissuade victims from seeking justice (Ryzik, Buckley, and Cantor 2017), his peers' respect for his authenticity appeared to normalize his behavior and delay publicity concerning his malfeasance and, thus, sanction. While authenticity influences how observers receive malfeasance (Hahl, Zuckerman, and Kim 2018), I argue that it proves consequential in the early stages of scandal by defining which acts constitute transgressions and thus attract publicity. 
Joke theft among stand-up comics also highlights some hazards and inefficiencies that arise when communities self-govern through norm-based systems and informal institutions. Without clear standards for defining transgressions and corresponding sanctions, community enforcement likely proves ineffective (King and Lenox 2000; Short and Toffel 2010). I find that this kind of enforcement often leads enforcers to rely on the qualities and behavior of the accused when determining blameworthiness. Social actors whose peers perceive them as authentic members of the community receive enhanced lenience, and they could conceivably exploit this leeway. This can constitute an alternative form of preference that resembles hierarchical domination in its effects (Fukuyama 2011; Martin 2009; Weber 1978). While norm-based systems may prove more flexible and less costly for community members (Ellickson 1991; Fauchart and von Hippel 2008; Oliar and Sprigman 2008; E. Posner 2000), they must also use adequate measures to ensure that conditionality does not enable malfeasance. 


\section{Works Cited}

Adut, Ari. 2005. "A Theory of Scandal: Victorians, Homosexuality, and the Fall of Oscar Wilde." American Journal of Sociology 111:213-48.

Aspers, Patrick and Frederic Godart. 2013. "Sociology of Fashion: Order and Change." Annual Review of Sociology 39:171-192.

Axelrod, Robert. 1986. "An Evolutionary Approach to Norms." American Political Science Review 80:1095-1111.

Bartley, Tim and Curtis Child. 2014. "Shaming the Corporation: The Social Production of Targets and the Anti-Sweatshop Movement." American Sociological Review 79:653-679.

Becker, Howard S. 1963. Outsiders: Studies in the Sociology of Deviance. New York: Free Press. . 1982. Art Worlds. Berkeley, CA: University of California Press.

Bernstein, Lisa. 1992. "Opting out of the Legal System: Extralegal Contractual Relations in the Diamond Industry." The Journal of Legal Studies 21:115-157.

Bicchieri, Cristina. 2006. The Grammar of Society: The Nature and Dynamics of Social Norms. Cambridge, UK: Cambridge University Press.

Bourdieu, Pierre. 1993. The Field of Cultural Production: Essays on Art and Literature. New York, NY: Columbia University Press.

Carroll, Glenn R. and Anand Swaminathan. 2000. "Why the Microbrewery Movement? Organizational Dynamics of Resource Partitioning in the U.S. Brewing Industry." American Journal of Sociology 106:715-762.

Carroll, Glenn R. and Dennis Ray Wheaton. 2009. "The Organizational Construction of Authenticity: An Examination of Contemporary Food and Dining in the U.S." Research in Organizational Behavior 29:255-282.

Centola, Damon, Robb Willer, and Michael Macy. 2005. “The Emperor's Dilemma: A Computational Model of Self-Enforcing Norms." American Journal of Sociology 110:10091040.

Coleman, James S. 1990. Foundations of Social Theory. Cambridge, MA: Harvard University Press.

DeLand, Michael F. 2013. "Basketball in the Key of Law: The Significance of Disputing in Pick-Up Basketball." Law and Society Review 47:653-685.

Di Stefano, Giada, Andrew A King, and Gianmario Verona. 2015. "Sanctioning in the Wild: Rational Calculus and Retributive Instincts in Gourmet Cuisine." Academy of Management Journal 58:906-931.

Durkheim, Emile. 1982. Rules of Sociological Method and Selected Texts on Sociology and Its Method, 2nd ed. Edited by Steven Lukes. Translated by WD Halls. New York: Free Press.

Ellickson, Robert C. 1991. Order Without Law: How Neighbors Settle Disputes. Cambridge, MA: Harvard University Press.

Emerson, Richard M. 1962. "Power-Dependence Relations." American Sociological Review 27:31-41.

Fauchart, Emmanuelle and Eric von Hippel. 2008. "Norms-Based Intellectual Property Systems: The Case of French Chefs." Organization Science 19:187-201.

Faulkner, Robert R. 2011. Corporate Wrongdoing and the Art of the Accusation. New York: Anthem Press. 
Fine, Gary Alan. 2001. "Enacting Norms: Mushrooming and the Culture of Expectation and Explanations.” Pp. 139-164 in Social Norms, edited by M. Hechter and K.D. Opp. New York,: Russell Sage.

. 2004. Everyday Genius: Self-Taught Art and the Culture of Authenticity. Chicago, IL: University of Chicago Press.

Frake, Justin. 2017. "Selling Out: The Inauthenticity Discount in the Craft Beer Industry." Management Science 63:3930-3943.

Frank, Robert H. 1988. Passions Without Reason: The Strategic Role of Emotions. New York: Norton.

Friedman, Sam. 2014. Comedy and Distinction: The Cultural Currency of a 'Good' Sense of Humor. London: Routledge.

Frith, Simon. 1996. Performing Rites: On the Value of Popular Music. Cambridge, MA: Harvard University Press.

Fukuyama, Francis. 2011. Origins of Social Order: From Prehuman Times to the French Revolution. New York: Farrar, Straus and Giroux.

Gardner, Eriq. 2016. “'Blurred Lines’ Appeal Gets Support From More Than 200 Musicians” Hollywood Reporter, August 30: Retrieved September 7 , 2017

(https://www.hollywoodreporter.com/thr-esq/blurred-lines-appeal-gets-support-924213).

Garfinkel, Harold. 1967. Studies in Ethnomethodology. New York, NY: Wiley.

Gibbs, Jack P. 1965. "Norms: The Problem of Definition and Classification." American Journal of Sociology 70:586-594.

Godart, Frederic. 2012. Unveiling Fashion: Business, Culture, and Identity in the Most Glamorous Industry. New York: Palgrave-Macmillan.

Goffman, Erving. 1974. Frame Analysis: An Essay on the Organization of Experience. Boston, MA: Northeastern University Press.

Granovetter, Mark. 1985. "Economic Action and Social Structure: The Problem of Embeddedness." American Journal of Sociology 91:481-510.

Grazian, David. 2005. Blue Chicago: The Search for Authenticity in Urban Blues Clubs. Chicago, IL: University of Chicago Press.

Hahl, Oliver. 2016. "Turning Back the Clock in Baseball: The Increased Prominence of Extrinsic Rewards and Demand for Authenticity." Organization Science 27:929-953. and Ezra W Zuckerman. 2014. "The Denigration of Heroes? How the Status Attainment Process Shapes Attributions of Considerateness and Authenticity." American Journal of Sociology 120:504-554.

, Ezra W Zuckerman, and Minjae Kim. 2018. "The Authentic Appeal of the Lying Demagogue: Proclaiming the Deeper Truth about Political Illegitimacy.” American Sociological Review 83:1-33.

Haidt, Johnathan. 2012. The Righteous Mind: Why Good People Are Divided by Politics and Religion. New York: Vintage Books.

Hechter, Michael and Karl-Dieter Opp. 2001a, eds. Social Norms. New York: Russell Sage. . 2001b. "What Have We Learned About the Emergence of Social Norms?" Pp 394-415 in Social Norms, edited by Michael Hechter and Karl-Dieter Opp. New York: Russell Sage.

Heckathorn, Douglas D. 1990. "Collective Sanctions and Compliance Norms: A Formal Theory of Group-Mediated Social Control.” American Sociological Review 55:366-384. 
Horne, Christine. 2007. "Explaining Norm Enforcement." Rationality and Society 19:139-170. . 2009. The Rewards of Punishment: A Relational Theory of Norm Enforcement. Stanford, CA: Stanford University Press.

Jasso, Guillermina and Karl-Dieter Opp. 1997. "Probing the Character of Norms: A Factorial Survey Analysis of the Norms of Political Action." American Sociological Review 62:947-964.

Jefferies, Michael P. 2017. Bebind the Laughs: Community and Inequality in Comedy. Stanford, CA: Stanford University Press.

Jerolmack, Colin and Shamus R Khan. 2014. "Talk is Cheap: Ethnography and the Attitudinal Fallacy." Sociological Methods Research 43:178-209

Johnston, Josée and Shyon Baumann. 2007. "Democracy versus Distinction: A Study Omnivorousness in Gourmet Food Writing." American Journal of Sociology 113:165-204.

Kim, Minjae and Ezra W. Zuckerman. 2017. "Faking It Is Hard to Do: Entrepreneurial Norm Enforcement and Suspicions of Deviance.” Sociological Science 4:580-610.

King, Andrew A, and Michael J Lenox. 2000. "Industry Self-Regulation Without Sanctions: The Chemical Industry's Responsible Care Program." Academy of Management Journal 43:698-716.

Knoedelseder, William. 2009. I'm Dying Up Here: Heartbreak and High-Times in Comedy's Golden Era. New York, NY: Public Affairs.

Lamont, Michelle. 2000. The Dignity of Working Men: Morality and the Boundaries of Race, Class, and Immigration. Cambridge, MA: Harvard University Press.

Lena, Jennifer C. 2012. Banding Together: How Communities Create Genres in Popular Music. Princeton, NJ: Princeton University Press. and Richard A. Peterson. 2008. "Classification as Culture: Types and Trajectories of Music Genres.” American Sociological Review 73:697-718.

Lieber, Chavie. 2018. "Fashion Brands Steal Design Ideas All the Time. And It's Completely Legal." Vox, April 28: Retrieved May 15, 2017 (https://www.vox.com/2018/4/27/17281022/fashion-brands-knockoffs-copyright-stolendesigns-old-navy-zara-h-and-m).

Lizardo, Omar, Robert Mowry, Brandon Sepulvado, Marshall A. Taylor, Justin Van Ness, and Michael Wood. 2016. "What Are Dual Process Models? Implications for Cultural Analysis in Sociology." Sociological Theory 34:287-310.

Maron, Marc. 2011. “Episode 161-Joe Rogan.” WTF Podcast, March 28: Retrieved March 30, 2011 (http://www.wtfpod.com/podcast/episodes/episode_161_-_joe_rogan).

Martin, John Levi. 2009. Social Structures. Princeton, NJ: Princeton University Press.

McDonnell, Mary-Hunter and Brayden G. King. 2018. "Order in the Court: How Firm Status and Reputation Shape the Outcomes of Employment Discrimination Suits." American Sociological Review 83:61-87.

Mears, Ashley. 2012. Ethnography as precarious work. The Sociological Quarterly 54:20-34.

Menger, Pierre-Michel. 2014. Economics of Creativity. Cambridge, MA: Harvard University Press.

Oliar, Dotan and Christopher Sprigman. 2008. "There's No Free laugh (anymore): The Emergence of Intellectual Property Norms and the Transformation of Stand-up Comedy." Virginia Law Review 94: 1787-1867. 
Ostrom, Elinor. 1990. Governing the Commons? The Evolutions of Institutions for Collective Action. Cambridge, MA: Cambridge University Press.

Peterson, Richard A. 1997. Creating Country Music: Fabricating Authenticity. Chicago: University of Chicago Press.

Phillips, Damon J, Catherine J. Turco, and Ezra W. Zuckerman 2012. "Betrayal as Market Barrier: Identity-Based Limits to Diversification among High-Status Corporate Law Firms.” American Journal of Sociology 118:1023-1054.

Posner, Eric A. 2002. Law and Social Norms. Cambridge, MA: Harvard University Press.

Posner, Richard A. 2007. The Little Book of Plagiarism. New York: Pantheon.

Reilly, Patrick. 2017. "The Layers of a Clown: Career Development in Cultural Production Industries." Academy of Management Discoveries 3:145-164.

Ridgeway, Cecilia and Shelly J. Correll. 2006. "Consensus and the Creation of Status Beliefs." Social Forces 85:431-453.

Rosen, Sherwin. 1981. “The Economics of Superstars.” American Economic Review 71:845-858.

Ryzik, Melena, Cara Buckley, and Jodi Kantor. 2017. "Louis CK Is Accused by 5 Women of Sexual Misconduct." New York Times, November 9, 2017.

Short, Jodi H and Michael W Toffel. 2010. "Making Self-Regulation More Than Merely Symbolic: The Critical Role of the Legal Environment." Administrative Science Quarterly 55:361-396.

Stebbins, Robert A. 1992. The Laugh-Makers: Stand-Up Comedy as Art, Business, and Life-Style. Montreal, QC: McGill-Queen's University Press.

Strauss, Anslem L and Judith Corbin. 2007. Basics of Qualitative Research: Techniques and Procedures for Developing Grounded Theory, 3rd ed. Los Angeles: SAGE.

Tavory, Iddo and Stefan Timmermans. 2014. Abductive Analysis: Theorizing Qualitative Research. Chicago, IL: University of Chicago Press.

Thornton, Sarah. 1996. Club Cultures: Music, Media, and Subcultural Capital. Hanover: Wesleyan University Press.

Tripoli, Sam and Brian Redban. 2011. "Naughty Show \#23." The Naughty Show, May 27: Retrieved January 10, 2012 (http://www.deathsquad.tv/naughty-show-23/).

Turner, Ralph H. 1976. "The Real Self: From Institution to Impulse.” American Journal of Sociology 81:989-1016.

Uzzi, Brian. 1997. "Socal Structure and Competition in Interfirm Networks: The Paradox of Embeddedness.” Administrative Science Quarterly 42:35-67.

Vaisey, Stephen. 2009. "Motivation and Justification: A Dual-Process Model of Culture in Action." American Journal of Sociology 114:1675-1715.

Van Maanen, John and Stephen Barley. 1984. "Occupational Communities: Culture and Control in Organizations." Research in Organizational Behavior 6: 287-365.

Vaughan, Diane. 2014. “Analogy, Case, and Comparative Social Organization.” Pp. 61-84 in Theorizing in Social Science: The Context of Discovery, edited by Richard Swedberg. Stanford, CA: Stanford University Press.

Weber, Max. 1978. Economy and Society. Edited by Guenther Roth and Claus Wittich. Berkeley: University of California Press. 
Wherry, Frederick. 2008. Global Markets and Local Handicrafts: Thailand and Costa Rica Compared. Baltimore: Johns Hopkins University Press.

Willer, Robb, Ko Kuwabara, and Michael W Macy. 2009. “The False Enforcement of Unpopular Norms." American Journal of Sociology 115:451-490.

Zuckerman, Ezra W, Tai-Young Kim, Kalinda Ukanwa, and James von Rittmann. 2003. "Robust Identities or Nonentities? Typecasting in the Feature-Film Labor Market." American Journal of Sociology 108:1018-1074. 


\begin{tabular}{c|c|l|}
\multicolumn{2}{c}{ Clarity of Transgressions } \\
Muthenticity & \multicolumn{1}{c}{ Murky } & \multicolumn{1}{c}{ Definite } \\
\cline { 2 - 3 } High & $\begin{array}{l}\text { Louis CK; Ted; } \\
\text { Amy Schumer }\end{array}$ & Manny; Max \\
\hline Low & Dane Cook & $\begin{array}{l}\text { Carlos Mencia; } \\
\text { Troy }\end{array}$ \\
\cline { 2 - 3 }
\end{tabular}

Figure 1: Exemplary cases concerning joke theft arranged by reputation for misappropriation and local perceptions of a comic's authenticity. 


\section{Appendix 1: Interview Sample}

The following table outlines the characteristics of my sample of interviewees and information about the interviews.

Table A1: Characteristics of Interviews and Subjects

\begin{tabular}{|c|c|c|c|c|c|c|}
\hline Pseudonym & $\begin{array}{c}\text { Years of } \\
\text { Experience }\end{array}$ & Sex & $\begin{array}{l}\text { Active at } \\
\text { Time of } \\
\text { Interview }\end{array}$ & $\begin{array}{c}\text { Active as of } \\
2015\end{array}$ & $\begin{array}{c}\text { Date of } \\
\text { Interview }\end{array}$ & $\begin{array}{l}\text { Interview } \\
\text { Length } \\
\text { (min) }\end{array}$ \\
\hline Allison & 5.5 & $\mathrm{~F}$ & Yes & Yes & Aug., 2011 & 78 \\
\hline Anthony & 5 & $\mathrm{M}$ & Yes & $\begin{array}{r}\text { No } \\
\text { (Deceased) }\end{array}$ & Sep., 2011 & 78 \\
\hline Brock & 1 & M & Yes & Semi & Nov., 2010 & 45 \\
\hline Charlie & 6 & M & Yes & No & Jul., 2011 & 71 \\
\hline David & 5 & M & No & No & Dec., 2013 & 70 \\
\hline Elliot & 6 & M & Yes & Yes & Jul., 2011 & 111 \\
\hline Inder & 7 & M & Yes & Yes & Nov., 2010 & 59 \\
\hline Jennifer & 4 & $\mathrm{~F}$ & Yes & Yes & Mar., 2013 & 60 \\
\hline Joe & 4 & M & Yes & Yes & Jul., 2012 & 69 \\
\hline Jonathan & 10 & M & Yes & Yes & Mar., 2013 & 79 \\
\hline Joshua & 2.5 & M & Yes & Yes & Aug., 2011 & 104 \\
\hline Kirk & 4 & M & No & No & Dec., 2013 & 66 \\
\hline Luther & 23 & M & Yes & Yes & Nov., 2010 & 53 \\
\hline Malcolm & 3.5 & $\mathrm{M}$ & Yes & Yes & Aug., 2011 & 64 \\
\hline Medha & 5.5 & $\mathrm{~F}$ & Yes & Yes & Aug., 2011 & 75 \\
\hline Mike & 7 & M & Yes & No & Nov., 2010 & 86 \\
\hline Mitch & 3 & M & Yes & Semi & Jul., 2011 & 69 \\
\hline Paul & 25 & M & Yes & Yes & Oct., 2011 & 91 \\
\hline Peyton & 2 & M & Yes & $\mathrm{No}$ & Dec., 2013 & 69 \\
\hline Rahul & 6 & M & Yes & Yes & Dec., 2011 & 64 \\
\hline Raza & 0.75 & M & Yes & $\mathrm{No}$ & Oct., 2010 & 51 \\
\hline Rick & 34 & M & Yes & Yes & Jul., 2012 & 77 \\
\hline Sabrina & 10 & $\mathrm{~F}$ & No & No & Jan., 2014 & 63 \\
\hline Shane & 23 & M & Yes & Yes & Nov., 2010 & 82 \\
\hline Taylor & 3 & M & Yes & Semi & Nov., 2010 & 55 \\
\hline Terrance & 5 & M & Yes & Yes & Oct., 2010 & 80 \\
\hline Tom & 13 & M & Yes & Yes & Nov., 2010 & 56 \\
\hline Tre & 2 & M & Yes & Yes & Nov., 2010 & 61 \\
\hline Wayne & 7 & M & Yes & Yes & Aug., 2011 & 113 \\
\hline William & 4 & $\mathrm{M}$ & Yes & Yes & Nov., 2010 & 64 \\
\hline
\end{tabular}

